\title{
Valorization of the tomato to obtain a powder rich in antioxidant constituents
}

\author{
Mennouche, D. ${ }^{\text {a,b,*} ; ~ B o u b e k r i, ~ A . ~}{ }^{\text {a,c }}$; Bouchekima, B. ${ }^{\text {a,d }}$; Boughali, S. ${ }^{\text {a,f }}$; \\ Moumeni, R. ${ }^{\text {a,b }}$; Boutadjine, D. ${ }^{\text {a }}$ \\ a Université Kasdi Merbah Ouargla, Laboratoire de Développement des Energies Nouvelles et \\ Renouvelables dans les Zones Arides et Sahariennes Ouargla 30000, Algeria. \\ b Département de Génie des Procédés, Université Kasdi Merbah Ouargla 30000, Algeria

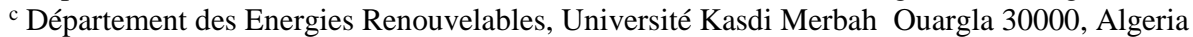 \\ e Département de Génie Mécanique, Université Kasdi Merbah Ouargla 30000, Algeria. \\ ${ }^{\text {f }}$ Département de Physique, Université Kasdi Merbah Ouargla 30000, Algeria.
}

*E-mail of the corresponding author: mennouche@gmail.com; mennouche.dj@univ-ouargla.dz

\begin{abstract}
The tomato (Lycopersicon esculentum), widely consumed fresh fruit but also in processed form, is recognized for its nutritional qualities, rich in micro components, such as carotenoids (lycopene in particular), phenolic compounds and vitamin $C$.

The goal of this work is to valorize the tomato; in the form of paste, seeds, peel and mixture of seeds-peel; in order to obtain a powder rich in antioxidant constituents. Convective drying of the various tomato by-products (paste, seeds, peel and mixture) is an essential process in the valorization of the studies products. The results obtained, showed that our analysed samples are rich in phenolic compounds. The mixture seeds-peel has slightly higher total polyphenol content (190.65 mg EAG / ml), peel (157.36 mg EAG / ml), seeds (140.56 mg EAG / ml) and the paste $(120 \mathrm{mg}$ EAG / ml).

The evolution of the color of dried by-products (method $L, a, b$ ), shows that the mixture (seeds-peel) has a better result of parameter "a" (indicates the red color and signifies the presence of Lycopene).
\end{abstract}

Keywords: tomato, drying, antioxidant, polyphenols. 


\section{Introduction}

Tomatoes are a major source of lycopene, which helps in the prevention of many chronic diseases such as cancer and heart diseases [1]. They also contain various nutritional (Vitamin A, C, and E), non nutritional (beta-carotene, carotenoid, flavonoids, flavone and total phenolic), minerals, and dietary fiber [2-3].

The very high water content of tomato (approximately 90\%) favors its degradation in the fresh state and its physical-chemical's and microbiological deterioration.

According to the Food and Agricultural Organization (FAO), the global production of tomato, in 2016, exceeds 177 million tons of which 1280570 tons were produced in Algeria.

The aim of this work is to valorize the tomato; in the form of paste, seeds, peel and mixture of seeds-peel; in order to obtain a powder rich in antioxidant constituents.

\section{Materials and methods}

\subsection{Drying experiments}

Drying experiments were performed on tunnel dryer (Fig.1) installed in the mechanical engineering laboratory, Ouargla University, Algeria. The dryer is a forced convection dryer intended for the drying of food products. Four removable stainless steel plates that can be placed in a channel (drying chamber) of dimension (250 cm x $50 \mathrm{~cm} \times 50 \mathrm{c} \mathrm{m}$ ). The drying chamber is thermally insulated with polystyrene (thickness $=3 \mathrm{~cm}$ ), the outer part of which is covered by four galvanized sheets. The drying of the different samples of tomatoes is carried out on a tray (surface of $620 \mathrm{~cm}^{2}$ ) and exposed to air flow, serves on the one hand to heat the product to be dried, and on the other hand, to evacuate the quantity of releasing moisture. The mass loss of product is controlled by a digital scale. The temperature and relative humidity of the air are detected by a combined temperature and humidity sensor. An additional sensor serves to measure the velocity of the air flow.

The air coming from the external environment is preheated by an electrical resistance. Under the effect of a fan with adjustable speed, drying air circulates in the drying chamber, passes through the product at a constant drying temperature and comes out at a lower temperature and high humidity.

\subsection{Sample preparation}

Fresh local tomatoes were bought from local market in Ouargla, Algeria. They were separated using a visual criterion like color, size, absence of physical damage and uniform maturation degree. The samples of different by-products were prepared according to the following steps : Fresh tomatoes were washed with water to eliminate dust, bacteria, dirt and insect larvae. Tomatoes were crushed using a Star Mix blender. The by-products: paste, 
seeds, peel and mixtures of seeds and peel were separated using a sieve ( $2 \mathrm{~mm}$ thickness) and dropped in a permeable bag for a few hours.

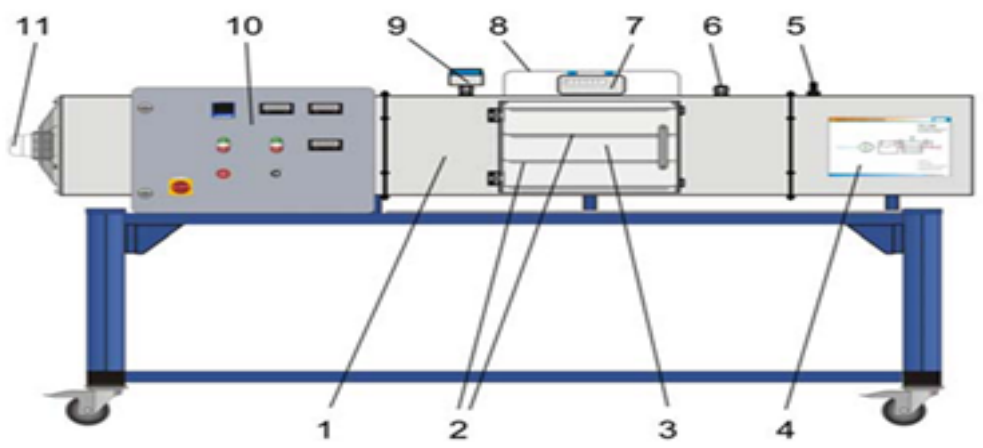

1. drying channe1, 2. drying racks, 3 . door, 4 . process schematic,

5 . air velocity sensor, 6 . measuring point for humidity and temperature, 7 . digital balance, 8 . bracket for drying plates, 9. measuring point with humidity and temperature sensor, 10. switch cabinet with digital displays, 11 . fan

Fig. 1. Drying system

\subsection{Moisture measurements}

Water content of different samples was determined using a moisture Analyzer (Sartorius MA 45 , accuracy \pm 0.01 ), operating in the following conditions:

Sample weight (3g); temperature analysis $\left(105^{\circ} \mathrm{C}\right)$. The device stops automatically once the weight of the sample becomes constant. Moisture content is expressed on a dry basis, $\mathrm{kg}$ water/kg dry matter.

\subsection{Total polyphenols analyses}

Total phenolic content of the samples was measured by the spectrophotometric method [4]. $5 \mathrm{~g}$ of the powder of each by-product is macerated in $100 \mathrm{ml}$ of a hydroalcoholic mixture $\mathrm{MeOH}$ (methanol-water) $(80 / 20: \mathrm{v} / \mathrm{v})$ for 48 hours at room temperature, after the methanol is evaporated by rotavapor at $65^{\circ} \mathrm{C}$ and the mixture is filtered by wattman paper to obtain a crude hydroalcoholic extract, finally the phenolic extract is kept at $6{ }^{\circ} \mathrm{C}$ until it is used. For the determination of total polyphenol, we introduce in a test tube $0.2 \mathrm{ml}$ of extract of each by-product of tomato (prepared in distilled water with suitable dilutions), $1 \mathrm{ml}$ of Folin- 
Cicalteu reagent (10 times diluted) and $0.8 \mathrm{ml}$ of the solution $\mathrm{Na}_{2} \mathrm{Co}_{3}$ at $7.5 \%$ (7.5 g in 100 $\mathrm{ml}$ ). The mixture is incubated at ambient temperature for two hours. The reading is performed against a blank without extract using a spectrophotometer at 765 Nanometer (nm).

\subsection{Antioxidant activity}

The evaluation of the antioxidant activity is based on the reduction reaction of $\left(\mathrm{Fe}^{+3}\right)$ present in the potassium ferrocyanide complex in $\left(\mathrm{Fe}^{+2}\right)$, the reaction is revealed by the yellowcolored transfer of ferric iron $\left(\mathrm{Fe}^{+3}\right)$ in green blue color of ferrous iron $\left(\mathrm{Fe}^{+2}\right)$, the intensity of this coloration is measured by spectrophotometer at $700 \mathrm{~nm}$. The experimental protocol [5] used is that of $0.5 \mathrm{ml}$ of sample of our extract at different concentrations is mixed with $1.25 \mathrm{ml}$ of a $0.2 \mathrm{M}$ phosphate buffer solution ( $\mathrm{pH} \mathrm{6.6)}$ and $1.25 \mathrm{ml}$ of a solution of potassium ferricyannide $\mathrm{K}_{3} \mathrm{Fe}(\mathrm{CN})_{6}$ at $1 \%\left(1 \mathrm{~g}\right.$ of $\mathrm{K}_{3} \mathrm{Fe}(\mathrm{CN})_{6}$ in $100 \mathrm{ml}$ of distilled water). Incubation of the prepared mixture in a water bath at $50^{\circ} \mathrm{C}$ for 20 minutes then the mixture is cooled. $2.5 \mathrm{ml}$ of $10 \%$ trichloroacetic acid is added to stop the reaction. $1.25 \mathrm{ml}$ of the supernatant is added to $1.25 \mathrm{ml}$ of distilled water and $0.25 \mathrm{ml}$ of a freshly prepared solution of $0.1 \%$ ferric chloride. The reading is against a white at $700 \mathrm{~nm}$.

\subsection{Color measurements}

The color of fresh and dried by-products was measured using a Minolta CR-400 colorimeter [6] allowing the acquisition of the Hunter $L, a, b$ color scale values. $L$ is lightness/darkness parameter, $a$ the redness/greenness one and $b$ the yellowness/blueness one.

Where $L_{0}, a_{0}$ and $b_{0}$ refer to the color values for the fresh by-producs of tomato.

\section{Results and discussion}

Fig. 2 illustrates the amount of total phenolics (TP) in various by-products of tomato. Our results showed that all the by-products of tomato are a good source of TP compounds.

The peel powder contained the highest level of TP compared to the powders of seeds and paste. The amounts of TP in peel powder increase $16,8 \%$ and $20,56 \%$ respectively to the seeds and paste powders. These results of this study are in accordance with Ramandeep et al. [7], who reported that the highest levels of total phenolics were detected in the peel of three tomato cultivars (Excell, Tradiro and Flavourine). In addition, this study has also identified the by-product of peel tomato as an important reservoir of TP compounds.

Fig. 2 shows also that the mixture (consisting of peel and seeds of tomatoes) powder contained the highest levels of TP compared to those of peel, seeds, and paste, powders.

This result shows that the mixture powder (peel and seed) is an important contributor to the major antioxidants of tomatoes. Therefore, removal of tomato peel and seeds during their fresh consumption or home cooking present a significant loss of the antioxidants. Similarly, 
the discard of tomato slurry (consisting of peel and seeds of tomatoes) during tomato processing industry means a loss of antioxidants.

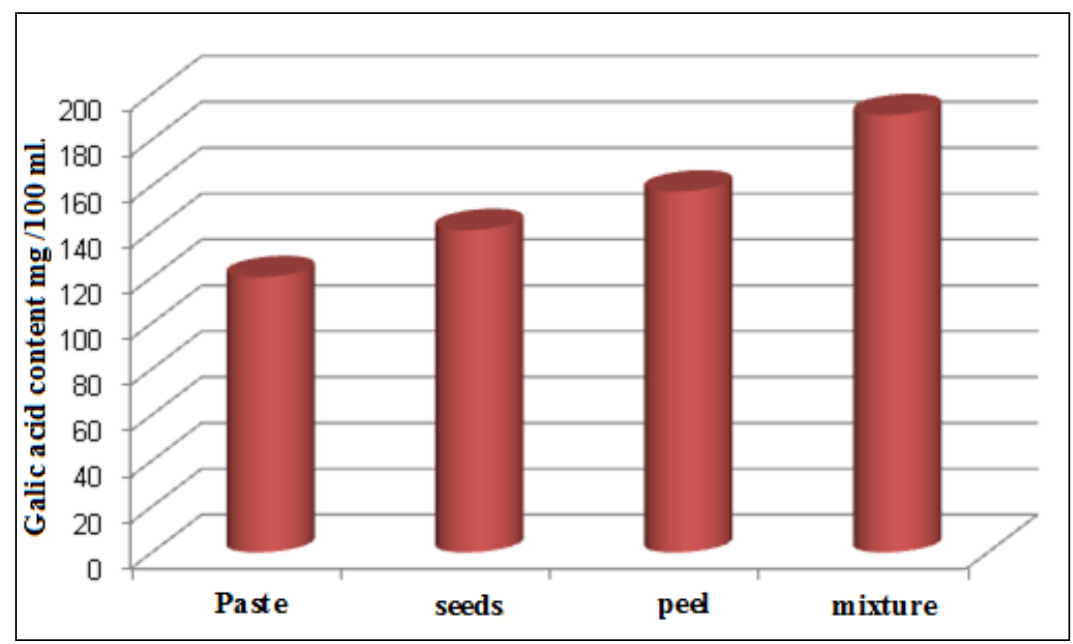

Fig. 2. Total polyphenol content of different by-products of tomato

The presence of the reductants in the extracts causes the reduction of iron $\mathrm{Fe}^{3+}$ ferricyanide complex to the ferrous form. Therefore, $\mathrm{Fe}^{2+}$ can be evaluated by measuring and monitoring the increase in green, blue colour density in the reaction medium at $700 \mathrm{NM}$. In other words, the $\mathrm{FeCl}_{3} / \mathrm{K}_{3} \mathrm{Fe}(\mathrm{CN})_{6}$ system confers on the method, the sensitivity for the determination of the polyphenol concentrations, which participate in the redox reaction [8]. According to the ascorbic acid curve, the reducing power of the four extracts is measured according to their absorbance.

The values presented in Figure 3 show the reducing power of the four extracts at different concentrations. From our results of the four extracts tested, an increase in iron reduction (increase in absorbance) is proportional to the concentrations used.

All our extracts have significantly lower antioxidant activity than that of the reference (ascorbic acid), for the latter the reduction is almost total from a concentration of $0.5 \mathrm{mg} /$ $\mathrm{ml}$. The extracts of the mixture powder (seeds and peel) is more active compared to the powders of the peel, the seeds, and the paste. The reducing power of the four extracts is due to the presence of lycopene and hydroxyl group in the phenolic compounds that can serve as electron donors. Therefore, antioxidants can be considered as reducing and inactivating oxidants. 


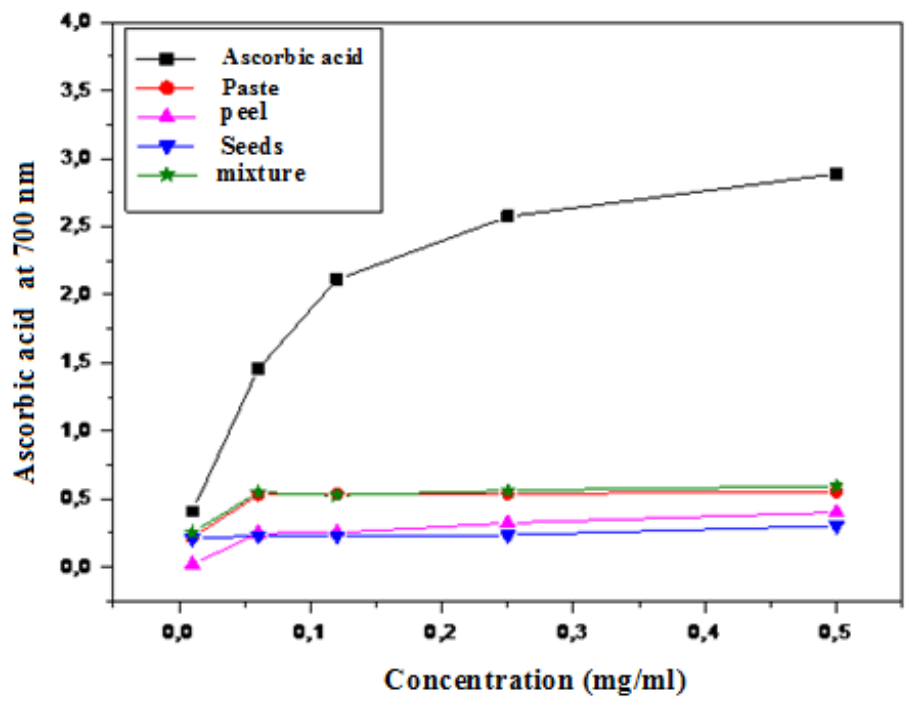

Fig. 3. Reducing power of the four extracts and ascorbic acid.

Figure 4 demonstrates the evolution of the coordinates ( $\mathrm{L}, \mathrm{a}, \mathrm{b})$ for the four by-products. It should be noted that the mean value of the a parameter ; indicates the red color and signifies the presence of Lycopene; in the mixture (S-P) was 40. Rosa et al [9]. reported that the increase of a parameter is directly associated with lycopene synthesis and a significant correlation was observed between lycopene and a. Marcos et al. [10] also, have found highly significant and exponential correlations between lycopene and a parameter. Based on the literature previously cited, it should be conclude that the lycopene content in the mixture (SP) presents a better result compared to the other by-products.

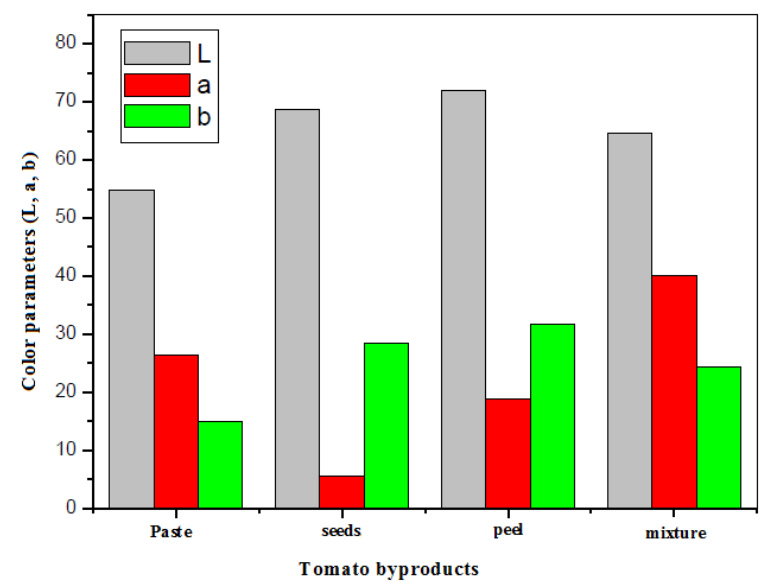

Fig. 4. Evolution of coordinates $(L, a, b)$ for the four by-products 
Mennouche, D.; Boubekri, A.; Bouchekima, B.; Boughali, S.; Moumeni, R. ; Boutadjine, D.

\section{Conclusion}

The valorization of the tomato; in the form of paste, seeds, peel and mixture of seeds and peel; to obtaining a powder rich in antioxidant constituents have been studied.

The convective drying of the various tomato by-products presents an indispensable step for the valorization of the tomato in powder form.

The results obtained showed that our analyzed samples are rich in phenolic compounds, whose mixture of seeds and peel has a slightly higher total polyphenol content (190.65 mg EAG / 100ml) compared to that of peel, seeds and paste which have 157.36, 140.56 and 120 mg EAG / 100ml respectively. This result confirms their high antioxidant potency which was proportional to different concentrations. This result has been confirmed by the color analyzes and the antioxidant

\section{References}

[1] C. Chawla, D. Kaur, D.P.S.Oberoi, D.S. Sogi. Drying caracterisics, sorption isotherms, and lycopene retention of tomato pulp. Drying Technology 26, 1257,1264, 2008.

[2] P. Rajkumar, S. Kulanthaisami, G.S.V. Raghavan, Y.Gariépy, V. Orsat. Drying kinetics of tomato slices in vacuum assisted solar and open sun drying methods. Drying Technology 25, 1349-1357, 2007.

[3] J. N. Davies, G. E. Hobson. The constituents of tomato fruit. The influence of environment, nutrition, and genotype. CRC Crit. Rev. in Food Sci. Nutri 15, 205-280, 1981. [4] Spanos, G. A., and Wrolstad, R. E. "Influence of processing and storage on the phenolic composition of Thompson seedless grape juice.” J. Agric. Food Chem. 38, 15651571. 1990.

[5] Ching-Hui Chang a,b, Hsing-Yu Lin b, Chi-Yue Chang b , Yung-Chuan Liu a. Comparisons on the antioxidant properties of fresh, freeze-dried and hot-air-dried tomatoes. Journal of Food Engineering 77, 478-485, 2006.

[6] Arslan, D., Ozcan, M. M., \& Menges, H. O.. Evaluation of drying € methods with respect to drying parameters, some nutritional and colour characteristics of peppermint (Mentha xpiperita L.). Energy Conversion and Management, 51, 2769-2775, 2010.

[7] Ramandeep K. Toor, Geoffrey P. Savage. Antioxidant activity in different fractions of tomatoes. Food Research International 38, 487-49, 2005.

[8] Amarowicz R, Estrella I, Hernandez T, Robredo S, Troszynska A, Kosinska A, Pegg R. Free radicals-scavenging capacity: antioxidant activity and phenolic composition of green lentil (Lens culinaris); Food Chemistry 121.705-711, 2010.

[9] Rosa Arias, Tung-Ching Lee, Logan Logendra, and Harry Janes. Correlation of Lycopene Measured by HPLC with the L*, a*, b* Color Readings of a Hydroponic Tomato and the Relationship of Maturity with Color and Lycopene Conten. J. Agric. Food Chem., 48, $1697-1702 ; 2000$. 
[10] Marcos Hernández, Elena Rodríguez, and Carlos Díaz. Free Hydroxycinnamic Acids, Lycopene, and Color Parameters in Tomato Cultivars. J. Agric. Food Chem., 55, 86048615. 2007. 